\title{
On Writing and Reading Artistic Computational Ecosystems
}

\author{
Rui Filipe Antunes***** \\ Universidade de Lisboa \\ Frederic Fol Leymarie ${ }^{\dagger}$ \\ William Latham ${ }^{\dagger}$ \\ University of London
}

\begin{abstract}
We study the use of the generative systems known as computational ecosystems to convey artistic and narrative aims. These are virtual worlds running on computers, composed of agents that trade units of energy and emulate cycles of life and behaviors adapted from biological life forms. In this article we propose a conceptual framework in order to understand these systems, which are involved in processes of authorship and interpretation that this investigation analyzes in order to identify critical instruments for artistic exploration. We formulate a model of narrative that we call system stories (after Mitchell Whitelaw), characterized by the dynamic network of material and conceptual processes that define these artefacts. They account for narrative constellations with multiple agencies from which meaning and messages emerge. Finally, we present three case studies to explore the potential of this model within an artistic and generative domain, arguing that this understanding expands and enriches the palette of the language of these systems.
\end{abstract}

Keywords

ALife, computational ecosystems, art

\section{Introduction}

Charles Darwin and Alfred Russel Wallace shocked the world in 1859 with On the Origin of Species and its explanation-in Thomas Kuhn's terms [18], one of the most significant paradigm shifts in human history. One and a half centuries later, a significant number of artists are working after being inspired by this revolutionary idea, combining it with further developments in scientific knowledge to produce novel, innovative, and artistic works. Some artists draw on ideas from scientific theories and experiments relating to evolution, genetics, self-organization, and emergence in order to inform their artistic practice. The subgenre of generative art that - inspired primarily by evolutionary computinghas appropriated principles of natural selection and genetics to drive the successive generations of artworks residing in computer memories is called Evo-Art [8]. This practice takes expression in an eclectic set of formats ranging from still digital imagery to full-fledged evolving environments (sonified, visualized in $2 \mathrm{D}$ or $3 \mathrm{D}$, interactive) presented in large-scale installations. This is now a well-established (digital) art practice, which has been surveyed by a number of authors in recent years $[29,7,25,8,19,6]$.

\footnotetext{
* Contact author.

*** BiolSI, Faculdade de Ciências, Universidade de Lisboa, Portugal. E-mail: rfantunes@fc.ul.pt

$\dagger$ Room 3, 29 St James, Department of Computing, Goldsmiths, University of London, New Cross, London SEI4 6NW, United Kingdom. E-mail: ff@gold.ac.uk (F.F.L.); w.latham@gold.ac.uk (W.L.)
} 
An important subdomain of Evo-Art is the practice where artists build computational ecosystems (CEs). These are software systems that include simulations of communities of individual agents emulating biological processes and behaviors, such that these agents are active in virtual worlds in search of, in particular, resources and reproductive partners. Individual agents typically gain, trade, or spend units of energy and may simulate predatory acts. They may also reproduce in a process where the offspring inherits some of the parents' features. These agents may also emulate metabolic cycles and eventually die and be removed from the simulation. Systems of this kind already have an established history in the field of ALife, going back at least to the early 1990s [6]. The artistic use of this technology exploits, for aesthetic purposes, the inherent dynamics generated by these communities. The outcomes are presented to the public in multiple formats, ranging from intimate experiences where users may navigate or interact with agents on their personal computers [2], to larger immersive audiovisual installations in gallery spaces where the human body may participate in the narrative, either by physical touch (via screens or other haptic devices) [26] or by having their movements in the gallery captured and mapped into the virtual space (via sensors) [15].

We present here a conceptual framework in order to understand such CEs. We want to examine the processes at play in these artefacts when they provide context and artistic meaning. What are the forms of communication and language? As artistic artefacts, they are involved in the processes of authorship and interpretation, which we analyze in order to identify the critical instruments for artistic exploration. We argue and formulate a model of narrative, which we call system stories after Mitchell Whitelaw [30], characterized by the dynamic network of material and conceptual processes that define these artefacts. This, we suggest, is a fundamental part of the processes of authorship and reading, since it is from within this complexity that meaning and messages emerge. Moreover, we present three case studies to explore the potential of this model within an artistic domain, and simultaneously we expand and enrich the language and palette available to artists using such systems. This is of critical importance for artists as well as for the overall community of producers, in view of the potential use of a CE as an instrument to animate general-purpose non-player characters (NPCs). We will emphasize this aspect when we present the development of the artwork Where is Lourenço Marques?, one of the three case studies discussed (Section 3.3).

\section{I.I Evolutionary Art and Computational Ecosystems}

Evo-Art established its roots in a methodological approach borrowed from computer science, that of evolutionary computation, where a syntactic element is transformed into its semantic representation; that is, an encoded blueprint (the genotype, or Gtype) is converted into its iconic or audible representation (the phenotype, or Ptype). The complexity of this conversion process is open to artistic creativity, and the linearity and metrics involved differ widely among practitioners. The diversity of the outcomes that this methodology entails is illustrated, for example by the computational evolutionary art pioneers William Latham and Karl Sims. Latham produces 3D morphologies based on a process of shape evolution, where the artist acts as a gardener selecting the samples to keep alive and mutate [27], while Sims uses genetic metaphors to generate abstract imagery based on a language of mathematical and visual operators [29].

One of the established ways in which the Gtype-Ptype paradigm has been explored is by applying this idea to whole populations of interacting autonomous agents in CEs. Each individual is initially represented and structured by the information written in its Gtype, and the individuals are then transformed into some phenotypic representation that usually has some metabolic cost associated with its operation. In a simple implementation this cost may be abstracted to a single health or energy value being decremented. Then, when organized in groups, agents become part of hierarchical food chains and trade units of energy amongst them. However, the complexity of this metabolic function varies from case to case, and-in some situations-works are organized around complex models of chemical transformations into biomass and waste. In addition, the autonomy of the individuals generates interesting dynamics of self-organization and emergence with cyclic changes of density. CEs used in Evo-Art explore the process of self-organization and emergence as the main mechanisms to 
generate heterogeneity and novelty in the works. In some cases, the Gtypes are directly sonified or visualized. Wakefield and Ji, for instance, produce sounds from the transcription of the Gtypes [28]. In other cases, the dynamics itself has been deemed interesting enough to be visualized or sonified; for example, the sonifications produced by Eldridge and Dorin result from the actions and status of the agents in the virtual space [11]. This is a healthy avenue of artistic practice (e.g., [22, $26,15,28,24])$.

Projects relying mainly on sonification often remain very abstract to an audience. Other projects, however, use explicit representation via visualizations of various shapes and imagery. In McCormack's Eden, for instance, agents and "biomass" have distinct visual traits allowing their identification as members of a particular class [22]. In such cases, the duality between the mechanistic processes taking place at the levels of hardware and software and the respective visualizations and consequent interpretations has the potential to be rendered explicitly as a function of the choices made by each system's designers.

In the next section, we will study in greater detail the representational system of CEs in order to understand how these processes contribute to the formation of meaning and context. One consequence will be that CEs may be instrumentalized not only by the community of artists interested in using them, but also by other designers of virtual worlds interested in their generative properties.

\section{Narrative Processes in CEs}

A critical part of human culture consists of maps of meaning [12]. These are shared systems of relationships of concepts together with codes that translate these concepts into language. These codes are social constructions and result from cultural conventions. To examine these modes of representation, it is helpful to explore the way semiotics considers language and signification. Semiotics, which is concerned with signs and their associated processes, allows the study of how systemic representations produce meaning in language and other cultural phenomena.

At the core of a cultural phenomenon, two systems cohabit: (i) a system of concepts that sets correspondence relationships between instances of people, objects, and events, thereby establishing a conceptual map, giving meaning to the world; and (ii) a mapping between the conceptual map and a set of signs that stand for associated concepts. The connection between concepts and signs is established by means of codes. As Stuart Hall reminds us in the first chapter of his book Representation: Cultural Representations and Signifying Practices, at the first level of representation, when we think of a tree, it is the linguistic code that tells us to use the English word "tree" [12]. Put simply, meaning is a result of the correlation between these three levels: the codes, the concepts, and the signs.

\section{I Semiotics and CEs}

Concepts and objects rarely have a fixed and permanent meaning of their own. The production of meaning depends on the processes of encoding and decoding or on an interpretation within a context, an environment, or a culture. The meaning we give to things is established via an interpretative framework. For example, consider a paper bag that could be recognized as a rubbish bag or a piece of art. In 2004, a bag containing discarded paper and cardboard, part of a work by Gustav Metzger being exhibited at Tate Britain in London, was accidentally thrown away by a zealous cleaner. Similar contextual processes occur in the realm of CEs.

Semiotics is a key instrument used to understand these artefacts through the analysis it produces using the notion of linguistic code. From the semiotic perspective, the reader is as important as the writer in providing meaning, where interpretation occupies the central role. A set of midlevel instructions in a typical software program implementing a CE might read as follows:

When the value of variable $a$ of the agent $k 1$ is less than a certain threshold, the list $b$ is inspected to find some other agent $k .2$ whose data structure has a pattern compatible to 
that of $k 1$. Once $k 2$ is found, then the variable $c$ of agent $k 1$ must adjust its current value to that of the variable $c$ of agent $k 2$ by an amount $x$.

At the semantic level, the same instructions might be described as follows:

A creature searching and finding a prey to hunt because it is hungry.

In the chapter "Narratives of Artificial Life" of her book How We Became Posthuman, Katherine Hayles stresses the active role of the viewer who fills the gaps in the narrative during the transition from the material to the imaginary spaces [13]:

These bodies of information are not, as the expression might be taken to imply, phenotypic expressions of informational codes. Rather, the "creatures" are their codes. For them, genotype and phenotype amount to the same thing; the organism is the code, and the code is the organism. By representing them as phenotypes, visually by giving them three-dimensional bodies and verbally by calling them ancestors, parasites, and such, [the ALife practitioner Thomas] Ray elides the difference between behavior, properly restricted to an organism, and executing a code, applicable to the informational domain. In the process, assumptions we have about behavior, in particular thinking of it as independent action undertaken by purposive agents, are transported into the narrative.

Multiple semiotic signs ${ }^{1}$ assemble to make meaningful the color change of two blue circles into red circles on the computer screen. A shared conceptual map is required for this transformation of pixels changing color into linguistic codes to be effective. It is left to interpretation to decode and read these changes on the computer screen as two creatures "becoming enraged and fighting in the context of the narrative of the CE." However, this transformation of blue circles into signs, as living beings (or at least as characters within the CE), is only part of the equation and happens in the first layer of representation. Stefen Helmreich argues that there is more at play in ALife. In his polemical book, Silicon Second Nature, he claims that the underlying narrative of CEs consists of representations of a 'neo-liberal' subject [14]. In this work, the author problematizes ALife, suggesting that by creating certain signifiers, that is, behaviors in the creatures, the authors are far from neutral. For instance, by inscribing only productive sex on their populations, designers of a particular CE are building a caricature of life. Helmreich argues that the wider cultural values that the ensemble of signs addresses are those from a restricted and specific ideology. In his view, these constructions, rather than the proclaimed motto of ALife: 'Life-as-it-could-be', are built from, as he puts it, specific 'visions of Life-as-we-know-it' [14].

Helmreich is referring to the Barthesian mythic level: ${ }^{2}$ the connotative quality of the works and the messages that this brings to a narrative. The implied social references inscribed by the designers/programmers on the behaviors of virtual entities play a central role in our discussion. Next, we consider how, in CEs, signs formulate connotations generating the narrative processes and contexts.

\footnotetext{
I Saussure is one of the key figures in linguistic structuralism and semiotics. For Saussure meaning is formed by a system of signs. At the material level, instances of the world exist as signifiers. The mental associations produced from these instances are their signifieds. In order to produce meaning, both signifier and signified are required to be present. It is the connection between these two levels that establishes the linguistic sign. These can be of arbitrary nature and are set by cultural practices: "there is no natural or inevitable link between the signifier and the signified" [12]. The language system, the general rules and codes, which the users must share, are referred to as the langue.

2 The operativity of the narrative was studied in depth by Roland Barthes. A classic example is an advertisement where a certain dress is associated with elegance. Having recognized the material as a dress and produced a sign, Barthes suggests a progress to a second level that links such a sign with wider cultural subjects such as "elegant" or "cool." Barthes calls the first and descriptive level denotation. The second and interpretative level is called connotation. Here, signs are interpreted in terms of the wider realm of social ideology. In his work Mythologies, Barthes provides an illustration of representation taking place through two separate but linked processes: At the first level (the elements of the image) signifiers and signifieds (a black man, clothing, one gesture, a flag) are united to form a sign, which denotes a message: A black soldier is giving the French flag a salute. At the second level, this message completes the sign by linking a set of signifieds with a broad ideological theme about French colonialism. Barthes calls this level of signification the myth.
} 


\subsection{Actors and Networks}

As a starting point, we consider the identification of two interpretative levels (denotative and connotative) provided by structuralist semiotics such as Barthes'. This allows us to understand CEs as providing three types of narrative processes: (i) signs for life forms permeated by structural gaps, which are filled by the reader (viewer, user), as advocated by Hayles; (ii) works that convey subtexts, messages carrying connotations at social levels, as Helmreich suggests; and (iii) open works in which the dynamic interaction of components generates new relationships in a potentially endless evolution. From this basis, we can now start to build a theoretical framework on which we can unfold the narrative processes of CEs and formalize their modes of functioning.

Flickering pixels on the screen might become "alive" when the conceptual map of the beholder provides a context where these same pixels signify living creatures (or their caricatures). However, how do we build these conceptual maps? These pixels correspond to actors in the actor-network theory, which proves to be useful for our discussion as it provides a material-semiotic account of interpretation that complements structuralist semiotics. One of its proponents, Bruno Latour, in the second chapter of Reassembling the Social, considers a sociological perspective where objects assume critical importance in the roles they play as part of human interaction and behavior. Objects, in this sense, are not simply the bearers of symbolic projections, but rather they become actors called to intervene in enactments taking place within networks composed of humans and nonhumans. For Latour, agency exists in different grades of causality: "there are many metaphysical shades between full causality and sheer inexistence." Objects, in this context, exist as actants waiting for networks, where they gain figuration, at which point they allow, permit, afford, inform, and so on, or in other words, they change a state of affairs by making a difference, and thus become actors. These networks of relations become established momentarily, and some of these actors may influence or make a difference in the course of some other actors' figurations within the network they are part of [20]. In this context, pixels on the screen do not have a set meaning. As Latour suggests, it is the context provided by the momentary network that provides these actants with their roles. As with the bag of cardboard displayed at the Tate gallery, the meaning of the pixels is contextual; they may be simple flickering dots or living creatures in an evolutionary struggle for survival, so that the reading is dependent on the current conceptual map. In the context of CEs, this map is also formed by a web of material and nonmaterial actors: pixels, 3D meshes, Web sites, the AI used, or the theory of natural selection; they all contribute to form a fluid combination of interactions in a network of forces and constraints operating simultaneously at various levels of interpretation.

To explain what are these main entities operating in our domain, it is helpful to invoke a taxonomy developed by Lisbeth Klastrup to study the poetics of virtual worlds. Klastrup is an internet theorist who, in her study of the worldness of virtual spaces, suggests an understanding of a (virtual) world "both as a fiction, a social space, a performative space and a special form of a game." In the process, she deconstructs the world into four functions as: (i) an interpretative framework, (ii) a prop, (iii) a simulation, and (iv) a lived narrative [17].

The world as an interpretative framework, or a fiction, is the shared contextual space and time, the concept or story behind the world. It constitutes a reference point from which the actions make sense; for instance, the story of its creation and evolution, the cosmology of its inhabitants [16]. As a shared prop, the audience engages within the world with a make-believe attitude, embodying an avatar representation or pretending to be someone else. In the function of simulation, the success of the navigation and interaction of the audience in the virtual space and with the virtual individuals depends on their knowledge of rules. ${ }^{3}$ Finally, the function of the world as a lived narrative or a story producer refers to aspects originated and experienced during the interactions with the world, understood as a stage for a shared experience [17].

\footnotetext{
3 Paideia (unstructured) and ludus (rule-based) are modes of play as defined by Roger Caillois [9], which are reinstated in virtual worlds as shared prop and simulation. These functions are proximal to gaming and performance. In paideia, players explore fantasy and escape reality, whereas ludus involves patience in learning skills and acting in a social context. These functions appear to be connected, in that in both situations the audience pretends to be "in" the world, interacting with the real objects and creatures in a game environment.
} 
Refining Klastrup's work, it might be important to extend the concept of the virtual space as a lived narrative to other contributing actants critically engaged in producing a story. CEs have intrinsic dynamics generated by the agency of the forms of ALife that inhabit them: the individual agents in the ecosystem. These interact autonomously and establish new relationships. New entities are originated in the system, others may disappear, and others may change their shape and form. CEs are dynamic, and they are in constant flux, which (re)generates the network of signifiers, composed of different graphical, auditive, and verbal signs, a web of actants participating in the process of interpretation, in accord with the above framework. This network articulates the events in the ecosystem with the Web site where the world is described, as well as with the processes in the rendering pipeline, or even with the vertices of a 3D surface. For example, in Technosphere, a $\mathrm{CE}$ is inhabited by entities configured by the users [24]; when users select their creature to be either a carnivore or a herbivore, they are actively participating in a narrative process that will unfold throughout the "lifetime" of that creature. The e-mails that the creature will send a posteriori, revealing who it has fought against or eaten, are some of the signifiers that will reinforce this dialectic.

CEs appear as such intrinsic spaces of mimesis and representation, where the worldness of the $\mathrm{CE}$ constitutes the foundational model of expression. Equating Klastrup's interpretative framework with diegetic processes, we can say that, in CEs, diegesis and mimesis appear combined. ${ }^{4}$ Echoing Hayles' gap between the material processes, at the electronic level, and the interpretation of those processes, with CEs, the characters rendered visible represent the internal data structures in an apparent mimetic process; however, their "second reality," as Caillois would put it [9], the realm where their actions are interpreted, is provided by the interpretative framework, the shared story where these actions make sense.

Fundamentally, CEs are defined as assemblages of material and nonmaterial elements, artefacts dependent on their generative mechanism, but equally subordinate to their context: the interpretative framework, the shared story, the simulation, the lived narrative. What emerges from this picture is that, at a software level, when detached from the typical narrative of "wolf-eats-rabbit-eats-grass," the essence of the $\mathrm{CE}$ is an abstract generative model of spontaneity, heterogeneity, and novelty.

\subsection{System Stories: A Worldness Narrative}

Equipped with this framework, we will now attempt to formalize a notion of narrative in CEs. "System stories" is a term we adopt from Mitchell Whitelaw [30] to describe the stories brought by artefacts made out of code. In his article "Systems Stories and Model Worlds: A Critical Approach to Generative Art" [30], Whitelaw suggests the notion for "a translation or narration of the procedural structures, ontology, entities and relations in a software system." In generative art, he sees an opportunity to engage with the more complex social and cultural systems in which we live. His interest is in the stories being conveyed by the subtext of these systems [30]:

But consider the subject or agent modeled here [in swarm systems], if that is the story we want to tell: a clone in a crowd, unchanging, with no traction on the space it inhabits, existing in an ongoing, perpetual present. If these systems provide images of contemporary society then they are, at best, naive and utopian.

Whitelaw is addressing the connotative level of the works. As discussed earlier, to consider the subtext we need to consider the contextual map and to do so we need to scrutinize the actors forming the network of relationships. Using the articulation of this concept and our previous

\footnotetext{
4 Diegesis is a mode of narration where a storyteller relates the experiences of the characters. Since Plato, this form of narration has been opposed to mimesis, in which the storytelling process illustrates the experiences of the characters by means of actions.

5 The design of the underlying formal system conditions the level of spontaneity, heterogeneity, and novelty. A CE can certainly generate novel outcomes within a certain range of possibilities, but that range is not infinite. For instance, if the structures of the genotypes define square-shaped individuals, then the domain for novelty of the phenotypes is restricted to that particular type of building block. The book Computers and Creativity offers a comprehensive overview of the theme [23].
} 
discussion, we can situate the narrative of CEs as the model of the story which emerges from a system of dynamic interactions.

Meaning in CEs relates to material processes, linguistic signs, and conceptual frameworks. The generative aspects of the system create new forms, shapes, and interactions. The narrative processes read these material entities and events within the context of the textuality of the CE. This includes a constellation of processes as diverse as the sounds being played, the rendered triangles in a 3D mesh of the landscape, the procedures modeling the agents' behaviors, or the text in the Web site where the work is accessed, or even the quality of the display or projection. Such heterogeneous material aspects combine in a Deleuzian mental automaton with the viewers accessing the work via their perceptual abilities, their awareness of the theory of natural selection, or their previous knowledge of computers. ${ }^{6}$ The resulting dynamic conjugation of textual and generative elements produces an ever-changing and almost fluid landscape where meaning is generated from the articulation of the material and the conceptual dimensions.

\section{Case Studies}

We now consider three case studies where the concept of system story is emphasized and used as an instrument for authorial expression.

In the first of these, Senhora da Graca [3], the materiality of the created virtual world is explored to convey a narrative of nostalgia and ecological loss by integrating the material properties of the textures and 3D geometries in the narrative. The second example, Vishnu's Dance of Life and Death [4], serves as a counterexample. This is used to exaggerate and illustrate the gap that exists between the material processes occurring in the software system and what can be rendered visible to the audience. A dance performance of humanoid avatars emphasizes this gap and enhances the importance of the interpretative framework in such artefacts. Finally, the third case study, Where is Lourenco Marques? [1,5], demonstrates the power implicit in the dissociation between software-electronic processes and the narrative. In this last example, the $\mathrm{CE}$ is used to generate the animations in a work that draws on European colonialism. The CE is used here as a metaphor for the social situation lived in a former colonial capital. A narrative of predatory behaviors of agents in the system becomes associated, at a connotative level, with the historical colonial narrative.

\section{I Senhora da Graça}

The artwork Senhora da Graşa is a memorial in the form of a virtual ecosystem composed of clouds of rain, soil, plants, herbivores, carnivores and scavengers [3]. Senhora da Graça was a valley, near Sabugal, in the northeast of Portugal, which in 2000 was submerged upon completion of a new dam. With the help of photographs taken at the site around 20 years ago, this work aims to reference a bygone era. The photographs are presented in a distorted and somewhat abstract way when projected as textures on the exterior surfaces of the 3D-generated creatures, as well as on the soil and in the skies of the virtual world. As the surfaces are not static, the generative dynamic of the interaction of creatures permanently rebuilds the world and the shapes. As a result, the photographs continue to make reference to a lost moment in time, but the dynamic frames where they are applied as 3D textures keep evolving, making them less and less recognizable. Having lost their pictorial value as photorealistic objects, they nevertheless maintain their conceptual and chromatic reference. In a metaphoric way, as happens with the submerged valley, in this work the photographs become unrecognizable, and ultimately they are altered memories of the event they evoke (Figure 1).

6 Gilles Deleuze, in his two volumes of work dedicated to cinema, suggests the "mental automaton": a feedback loop between a viewer and a cinematic work. This cybernetic circuit is initiated by the sensory stimuli of the electromagnetic pulses from the movie and the nerve signals and impulses that are generated in the viewer. Once this circuit is established, the impulses no longer come from the movie but from the circuits formed by the brain "mixing a multitude of cinematic signs with bodies" [10]. Some authors, such as John Law, argue that there is little difference between Deleuze's term "agencement" (translated by "assemblage") and the term "actor network" [2I]. 

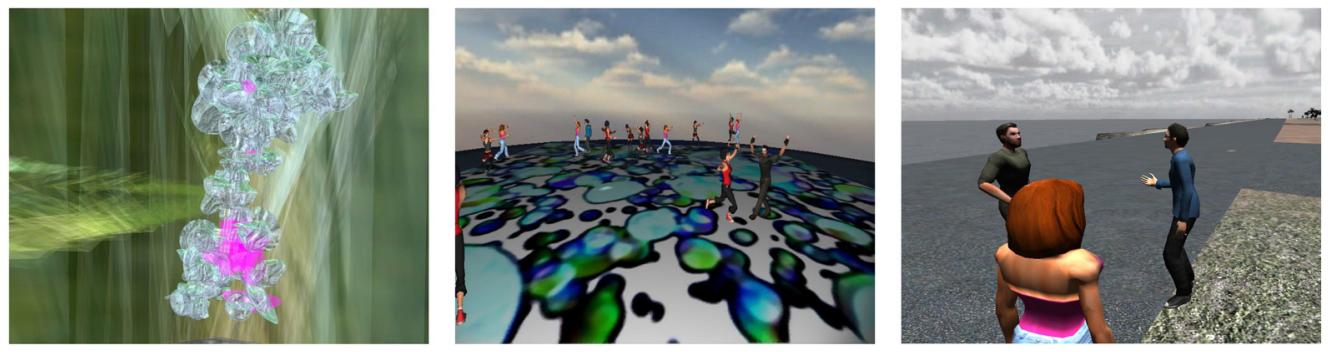

Figure I. Still images from: (left) Senhora da Graça, in which a population of virtual agents including plants, herbivores, and carnivores evolves [3]; (middle) Vishnu's Dance of Life and Death, a choreography for avatars or NPCs animated with a CE [4]; (right) Where is Lourenço Marques?, a virtual world where a CE animates a population of conversational humanoid agents [5].

Upon entering Senhora da Graca, a spectacle is offered, a parade of abstractions that the first-time viewer may have difficulty relating to any meaning. However, from the associated Web site the viewer/visitor has access to a text describing the intentions and motivations of the project, illustrated with an introductory short story. As if in an operatic performance, a libretto is required to help introduce and decode the narrative.

This libretto is key because it provides access to the interpretative framework. Due to its material properties (shapes, volumetrics, transparencies, and other pictorial elements of composition), the CE rendered visible in Senhora da Grasa has obvious interest as an isolated sculptural and material object. However, the semiotic signification is dependent on the textual narrative. This relation is not passive, and, as Latour suggests, the CE also prolongs, continues, and expands the narrative: The introductory text finds a natural follow-up in the deformation of the surfaces and the evolution of the creatures/pictures in the virtual ecosystem. In this sense, the CE has a dual and hybrid quality, since it is only complete when in the presence of another actant, the libretto (in the form of a Web site), its extension. Rather than ending with its set computational boundaries, the CE extends, and is extended by, other contributing actants to form the mental automaton.

\subsection{Vishnu's Dance of Life and Death}

This second case study functions to illustrate almost by absurdity, the gap emphasized by Hayles in the two-level operativity of CEs (Section 2.1). This work is an automatically generated choreography performed by humanoid agents in a virtual ecosystem. Here, the CE functions as the main mechanism driving the agents' movements and actions on stage. When designing Vishnu's Dance of Life and Death (Vishnu's Dance) [4], our motivation was to comment on ALife with a work where a virtual ecosystem provided context, content, and dynamics to the artwork. In Hindu mythological tradition, Vishnu is known as the "Preserver of the Universe." While two other major Hindu gods, Brahma and Shiva, are regarded respectively as the creator and the destroyer of the universe, Vishnu is the essence necessary for all beings, the force that maintains the universe. In an exploration of the narrative of life, part of the ALife framework, Vishnu's Dance is a stage performance where the sequence of movements in the choreography is dictated by an algorithm that simulates a CE. In an ironic artistic comment on the rhetoric of life surrounding ALife practice, the deity's role as maintainer of all existence appears here inscribed in the computational algorithm.

In Vishnu's Dance, 3D humanoid avatars perform a dance on a stage mimicking the evolutionary course of life (Figure 1). Avatars first appear from the sides of the stage and move towards a more central position, repeatedly executing the same movement. Then the choreography intensifies and the avatars play their parts with heterogeneous movements. They abandon the stage at different times while new dancers join the performance.

Since the environment consists of multiple avatars, the course of the performance is dictated by the autonomous interactions and evolution of the population. As a consequence, two different runs 
of the performance will provide different experiences for the audience. Sometimes it ends quickly; at other times it persists. Importantly, the dance is a visual representation of the ecosystem. That is, the performance on stage provides a very direct visualization of the underlying multi-agent state space, with a direct connection between the current state of the ecosystem and the configuration of the dancers on stage. Each avatar on stage is an individual belonging to the population. Each arrival to the scene is equivalent to a birth, while each exit represents a burial. Each interaction during the lifetime of an avatar is translated into a movement on stage. The algorithm establishes a correspondence between events in the ecosystem and the movements performed in the dance. With this model, the action of an avatar feeding in the virtual ecosystem might correspond to an arabesque, and its escape after a fight in the ecosystem's habitat might correspond to a jete on stage.

One of the immediate merits of this work is to make clear the importance the role played by some of the actants forming the shared conceptual map. Since there is no libretto, the interpretative framework is not fed with a substantial part of the usual narrative omnipresent in CEs, and the mental automaton lacks the signifiers to indicate life narratives. Instead, what is provided are actants misleading the mental automaton and what is rendered visible are humanoid dancers performing a wild choreography. The visualizations are consequences of the ecosystem but incongruent in terms of the (eco-)narrative. The work still draws ironically on these aspects, but it shows that, detached from the rhetoric of life, the CE is ultimately a computational model for the generation of dynamic heterogeneity and apparent spontaneity. It is left to the practitioners to bring in the appropriate actants to build narratives.

\subsection{Where is Lourenço Marques?}

The final case study illustrates the exploration of ecosystem dynamics at a connotative level of narrative. In the landscape of colonial Portugal, Lourenço Marques was the capital of the province of Mozambique. The city became known as Maputo after independence in 1975, and this work is a representation of that locale in the last days of the colonial era. This memorial takes expression in a mosaic of voices combining multiple forms of representation in a $3 \mathrm{D}$ virtual world. During the preliminary stage, interviews were conducted with a community of retornados who had to abandon the city and move to Portugal in the three-year period between 1974 and 1976. From the descriptions and materials shared during the interview process (such as oral accounts, drawings, photographs, and songs) a virtual place was built to be inhabited by a community of autonomous storytellers. These storytellers mediate and transmit the oral accounts of the participants to the audience $[1,5]$.

As with the previous example, Vishnu's Dance, the CE is used here to generatively animate a population of humanoid agents. However, in the tradition of literary allegory, the CE animating this autonomous population carries a subtext operating at the connotative level of signification. In a metaphorical association in the virtual world, social groups are equated with species competing in an ecosystem. This is used to illustrate the recent history of European colonialism. Individuals in the virtual city trade units of energy amongst each other in their struggle for survival. The movements and the actions in the virtual city are determined by the dynamics generated by their predatory acts in the system, competing for energy and the perpetuation of their genetic heritage (Figure 1). However, instead of the literal translation of actions into their respective animations of primal acts of fierce creatures attacking and eating each other, what is offered are individuals gesticulating in apparent social interaction. In a more recent version of the work, we can draw upon the two-layered organization of the ecosystem, with producers and consumers, to take advantage of the existing predator-prey dynamics in order to build a narrative depicting colonials and servants.

Individuals are identified by a genomelike string where each bit or combination of bits corresponds to certain phenotypic features. The sequence of bits in the genome establishes the metabolic pattern that defines the position of one individual in the hierarchy of the food chain. One sequence defines the chemical composition and a second sequence defines the metabolic possibilities for this individual. Thus, consumers may prey on producers as well as live on the energy from other 
consumers at lower hierarchical levels. When the genome has the servant gene, the individual in question becomes a producer. All the other individuals, without such an active gene, are consumers. These servant individuals work in agricultural plots, generating energy to feed themselves and others who may be higher in the food chain. When consumers are hungry, they search and hunt for prey.

When we read this description in the catalog accompanying the work, the author gains a voice expressed both in the textuality of the work and at its connotative level. This libretto emphasizes the subjective memory of the first-person accounts from the other participants, who experienced the original city first-hand, but who now have this experience mediated by their own memories. Far from being neutral, this voice/actant changes the ontology of the work. On the one hand, it transforms the work from being an archive of memorabilia mediated in 3D into a pure translation, expressing a particular vision of a historical social context. On the other hand, as the actor-network theory suggests, this voice also changes the nature of some of the other actants: the storytellers, the population of humanoid agents that inhabits the virtual city. These become, in the mental automaton, living creatures preying on each other in an ecosystem. The signifier of the behaviors/actions performed by the entities in the software is first mapped and rendered as specific gestures and movements of conversational humanoid agents, and then, by means of the other actants involved in the network-namely, the libretto explaining the present allegory (and the fact that other actants in the population are signifiers of humans) - this behavior is transported into the narrative of a recent past of colonial history and culture.

\section{Conclusions}

This article attempts to lay out a theoretical space for situating and experiencing CEs as instruments for wider artistic dialogues. This journey began with a work of deconstruction of the narrative processes in these artefacts. We have referred in particular to analyses from Hayles, Helmreich, Klastrup, Saussure, Barthes, and Latour to discuss this mode of representation. In the process, we have identified how a gestalt of material and conceptual elements collaborate, generating a field of interpretation. To fill the gap alluded to by Hayles, a series of actants are invoked by the artists/modelers. We argue that this gap is a good place for artistic creativity. We propose the term "system stories" (after Whitelaw [30]) to refer to this model of narrative constellations with multiple agencies. The first case study, Senhora da Graça (Section 3.1), assisted with the formulation of this model of narrative by emphasizing the material processes, which are instrumentalized into contextual and interpretative maps. This is suggested as a critical conceptual tool in understanding such works. A system story correlates the material properties within the context provided by the $\mathrm{CE}$ with semantic elements actively participating in the narrative process. This textual construction goes on to include a wide network of actants. This ranges from the coding language used in the implementation of the virtual system to the story read by the audience or even its processes of public dissemination. This construction is dynamic and ongoing. Due to their openness, works evolve with time when new relations and interactions unfold and become established within the network.

We also illustrated the dissociation of the operative mechanics of the system from the narratives of life. To assist in this process of separation between narrative and operative levels, we discussed Vishnu's Dance, an artefact where these two levels appear disjointed and somehow engaged in absurdity (Section 3.2). This separation provides a conceptual gap that offers a fertile territory to explore in narrative terms, and gives us the opportunity to argue that the essence of the $\mathrm{CE}$ is that of a generative model for spontaneity and heterogeneity in communities of general-purpose NPCs. The artwork Where is Lourenco Marques? depicts some of these possibilities, namely in the animation of a population of conversational humanoid NPCs (Section 3.3). This work explores the connotative level of interpretation to create a subtext and to articulate the CE in a wider sociopolitical context.

Reading CEs entails a complex articulation of material and nonmaterial processes, organized through the operation of codes within a syntactic domain. These artefacts are fundamentally generative instruments for heterogeneity and spontaneity, depending on a series of assembled actants 
whose forces are woven together to produce meaning. System stories are the narratives emergent from this dynamics; they are critical in the processes of authorship and interpretation. Messages are conveyed when artists model the material processes producing the $\mathrm{CE}$ and when they invoke other actants: first to build the diegesis, and then to bridge the gap with the material artefact.

\section{References}

1. Antunes, R. F. (2012). Where is Lourenço Marques?: A mosaic of voices in a 3D virtual world. Leonardo Electronic Almanac, 18(Touch and Go)(3), 114-121.

2. Antunes, R. F., \& Leymarie, F. F. (2008). xTNZ—an evolutionary three-dimensional ecosystem. In A. Barbosa (Ed.), Proceedings of the 4th International Conference on Digital Arts, artech 2008 (pp. 201-204).

3. Antunes, R. F., \& Leymarie, F. F. (2010). Epigenetics as aesthetic instrument in a generative virtual ecosystem. In L. Valbom (Ed.), Proceedings of the 5th International Conference on Digital Art, artech 2010 (pp. 172-176).

4. Antunes, R. F., \& Leymarie, F. F. (2012). Generative choreography: Animating in real time dancing avatars. In P. Machado, J. Romero, \& A. Carballal (Eds.), Proceedings of the First International Conference on Evolutionary and Biologically Inspired Music, Sound, Art and Design, evomusart 2012 (pp. 1-10).

5. Antunes, R. F., \& Leymarie, F. F. (2013). Real-time behavioral animation of humanoid non-player characters with a computational ecosystem. In R. A. et al. (Eds.), 13th Conference on Intelligent Virtual Agents (iva 2013), Inai 8108 (pp. 382-395). Springer.

6. Antunes, R. F., Leymarie, F. F., \& Latham, W. (2014). Two decades of evolutionary art using computational ecosystems and its potential for virtual worlds. Journal of Virtual Worlds Research, 7(3).

7. Bentley, P., \& Corne, D. (2002). Creative evolutionary systems. Academic Press.

8. Boden, M. A., \& Edmonds, E. A. (2009). What is generative art? Digital Creativity, 20(1\&2), 21-46.

9. Callois, R. (1961). Man, play and games. Free Press of Glencoe.

10. Deleuze, G. (1989). Cinema 2: The time-image. University of Minnesota Press.

11. Eldridge, A., \& Dorin, A. (2009). Filterscape: Energy recycling in a creative ecosystem. In M. Giacobini (Ed.), Proceedings of Evoworkshops on Applications of Evolutionary Computing (pp. 508-517). Springer-Verlag.

12. Hall, S. (Ed.) (1997). Representation: Cultural representations and signifying practices. SAGE Publications Ltd.

13. Hayles, K. (1999). How we became posthuman. The University of Chicago Press.

14. Helmreich, S. (1998). Silicon second nature: Culturing artificial life in a digital world. University of California Press.

15. Ji, H., \& Wakefield, G. (2012). Virtual world-making in an interactive art installation: Time of doubles. In S. Bornhofen, J. Heudin, A. Lioret, \& J. Torrel (Eds.), Virtual Worlds: Artificial Ecosystems and Digital Art Exploration (pp. 53-70). Science eBooks.

16. Klastrup, L. (2002). A virtual world aesthetics: Theorising multi-user textuality. In Proceedings of Internet Research 3.0. Maastricht, the Netherlands.

17. Klastrup, L. (2003). A poetics of virtual worlds. Fine Art Forum, 17(8).

18. Kuhn, T. S. (1962). The structure of scientific revolutions. The University of Chicago Press.

19. Lambert, N., Latham, W., \& Leymarie, F. F. (2013). The emergence and growth of evolutionary art, 1980-1993. Leonardo, 46(4), 367-375.

20. Latour, B. (2005). Reassembling the social: An introduction to actor-network-theory. Oxford University Press.

21. Law, J. (2004). After method: Mess in social science research. Routledge.

22. McCormack, J. (2001). Eden: An evolutionary sonic ecosystem. In J. Sosik \& P. Kelemen (Eds.), Advances in artificial life (pp. 133-142). Springer-Verlag.

23. McCormack, J., \& d 'Inverno, M. (Eds.) (2012). Computers and creativity. Springer.

24. Prophet, J. (1996). Sublime ecologies and artistic endeavors: Artificial life and interactivity in the online project "TechnoSphere." Leonardo, 29(5), 339-344. Retrieved from http://www.jstor.org/ stable/ 1576397 
25. Romero, J., \& Machado, P. (Eds.) (2007). The art of artificial evolution: A bandbook on evolutionary art and music. Springer-Verlag.

26. Sommerer, C., \& Mignonneau, L. (1994). A-Volve: A real-time interactive environment. In ACM SIGGRAPH visual proceedings (pp. 172-173).

27. Todd, S., \& Latham, W. (1992). Evolutionary art and computers. Academic Press.

28. Wakefield, G., \& Ji, H. (2009). Artificial nature: Immersive world making. In R. A. Brooks \& P. Maes (Eds.), Applications of evolutionary computing (pp. 377-381). Springer.

29. Whitelaw, M. (2004). Metacreation: Art and artificial life. MIT Press.

30. Whitelaw, M. (2005). Systems stories and model worlds: A critical approach to generative art. In Readme 100: Temporary Software Art Factory (pp. 135-154). Norderstedt. 


\section{AUTHOR QUERY}

\section{AUTHOR PLEASE ANSWER QUERY}

During the preparation of your manuscript, the question listed below arose. Kindly supply the necessary information.

1. Please check if the proposed running head is okay.

\section{END OF QUERY}

